\title{
Rate of recovery in motor and sensory fibres of the radial nerve: clinical and electrophysiological aspects ${ }^{1}$
}

\author{
W. TROJABORG
}

\begin{abstract}
From the Laboratory of Clinical Neurophysiology, University Hospital, Copenhagen, Denmark and the Department of Neurology, Hospital of the University of Pennsylvania, Philadelphia, Pennsylvania, U.S.A.
\end{abstract}

SUMMARY Electromyography and conduction studies in motor and sensory fibres were performed in 58 patients with different types of radial nerve injury. The site of nerve injury was predicted by clinical and electromyographic findings and correlated with changes in conduction, thereby permitting a more exact classification of the type of nerve injury. In patients with Saturday-night palsy, there was considerable slowing of conduction in both motor and sensory fibres across the presumed site of the lesion with return to normality within six to eight weeks. These observations suggest that local demyelination is the cause of nerve palsy. There were changes in sensory conduction even when there was no sensory deficit clinically, with no difference in susceptibility of motor and sensory fibres to ischaemia. In patients with radial nerve palsy secondary to fracture of the humerus, outgrowth in motor and sensory fibres was equal and estimated to be about $1 \mathrm{~mm}$ per day. When the radial nerve palsy was attributed to traction or mild blunt injury the site of lesion was based on clinical and electromyographic findings. The rate of conduction in motor and sensory fibres was normal, suggesting that axonal damage was the cause of paresis, with sparing of some of the fastest conducting fibres.

Voluntary and spontaneous muscle activity, and motor and sensory conduction velocity were recorded in 58 patients with different radial nerve disorders. The purpose of the study was to delineate possible differences between these disorders by electrophysiological criteria, with special emphasis on conduction in motor and sensory fibres in the acute phase of Saturday-night palsies and on conduction during recovery after partial or total interruption of the radial nerve secondary to fracture of the humerus.

In previous studies of Saturday-night palsy sensory conduction across the site of the lesion was normal if the nerve conducted impulses at all (Downie and Scott, 1964; Trojaborg and Sindrup, 1967). In these investigations, sensory fibres of the radial nerve were stimulated by surface electrodes placed at either the wrist or thumb.

In these circumstances simultaneous stimulation of fibres in the median nerve might interfere with recording of sensory action potentials over the radial nerve in the axilla, leading to the false im-

\footnotetext{
${ }^{1}$ In part supported by grant No. NB 08075-02.
}

pression of normal sensory conduction. The spread of the stimulus can be avoided by stimulating the radial nerve at the wrist with needle electrodes (Trojaborg and Sindrup, 1969).

\section{MATERIAL}

Fifty-eight patients were examined; they ranged in age from 9 to 72 years; 16 were females and 42 males. The injury of the radial nerve was caused by pressure during sleep in 29 patients, secondary to fracture in 17 (localized to the middle of the shaft of the humerus in 13, supracondylar in two, and in the forearm in two), attributed to blunt injury or traction in 11 , and of uncertain origin in one. The patients were first examined within one day to 12 months after the injury; 21 patients were examined twice or more.

\section{METHODS}

1 ELECTROMYOGRAPHY The electromyogram was recorded photographically with a three-channel electromyograph (DISA). Concentric needle electrodes were used for leading off from the brachial triceps, the brachioradialis, and the extensor digitorum communis muscles. The electromyographic criteria used were (1) pattern and amplitude of the action potentials at full effort; (2) signs 
of denervation-that is, spontaneous di- or triphasic potentials of 2 to $4 \mathrm{msec}$ duration and positive sharp waves or both, in more than two points of every muscle outside the end-plate zone; (3) mean duration of at least 20 different motor unit potentials; and (4) the number of polyphasic action potentials (Buchthal, 1957; Buchthal and P. Rosenfalck, 1966).

2 MOTOR AND SENSORY CONDUCTION The method has been described recently (Trojaborg and Sindrup, 1969). In short, the radial nerve was stimulated at two levels: at the elbow $6 \mathrm{~cm}$ proximal to the lateral epicondyle of the humerus, and at the axilla $18 \mathrm{~cm}$ above the medial epicondyle of the humerus. In some patients, conduction to the extensor indicis muscle was also determined by stimulating its nerve at the dorsal aspect of the forearm $8 \mathrm{~cm}$ above the styloid process of the ulna (Jebsen, 1966). The same electrodes used for stimulation of motor fibres were also used for recording sensory potentials.

Sensory fibres were stimulated by needle electrodes over the superficial branch of the radial nerve at the wrist and then by skin electrodes at the proximal phalanx of the thumb. When stimulating the thumb, contamination of the potential recorded above the radial nerve by potentials spread from the median nerve is inevitable, making it impossible to decide whether or not there is a complete block of radial nerve fibres. This is substantiated by recording potentials over the radial nerve when stimulating the distal phalanx of digit III (Fig. 1). Therefore, the present study included only cases in which stimulation of the radial nerve at wrist provided addiz tional information as to whether or not conduction was preserved. When the sensory action potential was less than $2 \mu \mathrm{V}$, an electronic averager was used on-line where ever possible; 500-1000 responses were averaged to gether with a calibration signal (Andersen, 1966). Foib control, the same number of sweeps were then average 8 with the electrodes in position but without stimulus.

The electrodes used for stimulation and recording an the method used to record the stimulus current have beep described previously (Buchthal and A. Rosenfalck, 1966):

TEMPERATURE To maintain constant temperature the hand, forearm, and arm were irradiated by an infra-ref heater. Temperature was measured by a thermocoupl on the skin and by a thermoneedle inserted near the nerveThe temperature at the thumb averaged $34 \pm 0 \cdot 2^{\circ} \mathrm{C}$, aळ the wrist $35 \pm 0.1^{\circ} \mathrm{C}$, at the elbow $36 \pm 0.1^{\circ} \mathrm{C}$, and if the axilla $35 \pm 0.2^{\circ} \mathrm{C}$.

\section{RESULTS}

1 CLINICAL OBSERVATIONS The radial nerve waş compressed during sleep in 29 patients. Of these the brachioradialis and the extensors of the wrist an\&w fingers were affected in 24 , varying from paralysis to moderate weakness at the time of the first inves tigation. In 18 there was sensory loss correspond官g to the posterior cutaneous nerve of the forearm

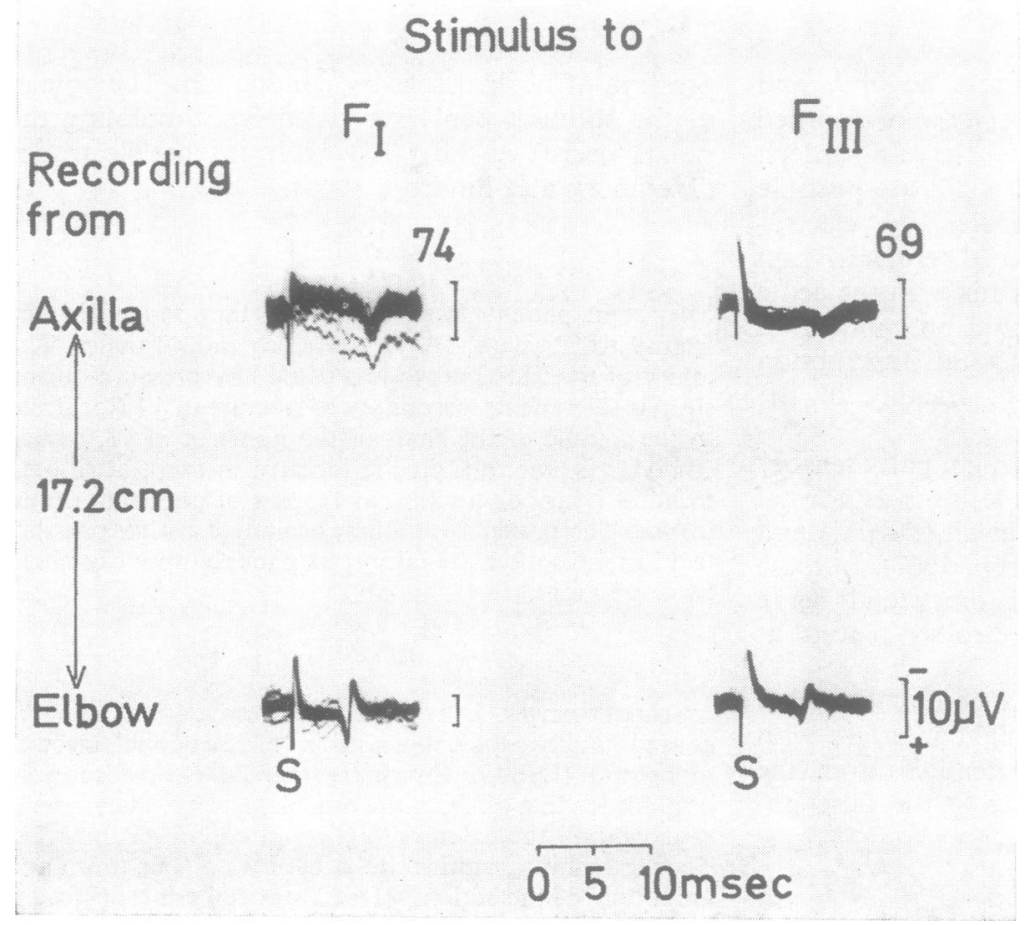

FIG. 1. Action potentials recorded over the radial nerve at the elbow and axilla when stimulating the digital nerves at the proximal phalanx of the thumb $\left(F_{I}\right)$ and at the distal phalanx of the middle finger $\left(F_{I I I}\right)$. Photographic superposition of 12 to 15 sweeps. Patient L.D. (EMG No. 12966), female, 18 years old with Saturday-night palsy for 13 days. Stimulus $(S)$ : $50 \mathrm{~mA}(20 \times \mathrm{Ts})$. Temperature near the nerve $36^{\circ} \mathrm{C}$. 
the superficial nerve, or both. In five patients paresis was confined to the extensor muscles of the wrist and fingers, with sensory loss in only one (Table 1). The brachial triceps muscle was spared in all the patients with sleep palsy.

\section{TABLE 1}

DISTRIBUTION OF MOTOR AND SENSORY LOSS IN 58 PATIENTS WITH RADIAL NERVE INJURY

\begin{tabular}{|c|c|c|c|c|c|}
\hline \multirow[t]{2}{*}{ Aetiology } & \multirow[t]{2}{*}{ Paresis of } & \multicolumn{3}{|c|}{$\begin{array}{c}\text { Sensory loss } \\
\text { (Hypaesthesia-hypalgesia) }\end{array}$} & \multirow{2}{*}{ Total } \\
\hline & & $\begin{array}{l}\text { Hand and } \\
\text { forearm }\end{array}$ & Hand & None & \\
\hline $\begin{array}{l}\text { Compression } \\
\text { during } \\
\text { sleep }\end{array}$ & $\begin{array}{l}\text { Brachioradialis } \\
\text { and extensor } \\
\text { muscles } \\
\text { Extensors of } \\
\text { wrist and fingers }\end{array}$ & $\begin{array}{l}7 \\
0\end{array}$ & $\begin{array}{r}10 \\
1\end{array}$ & $\begin{array}{l}7 \\
4\end{array}$ & $\begin{array}{r}24 \\
5\end{array}$ \\
\hline $\begin{array}{l}\text { Traction } \\
\text { or blunt } \\
\text { injury }\end{array}$ & $\begin{array}{l}\text { Brachioradialis } \\
\text { and extensor } \\
\text { muscles } \\
\text { Extensors of } \\
\text { wrist and fingers }\end{array}$ & $\begin{array}{c}11(8) \\
0\end{array}$ & $\begin{array}{l}7(4) \\
3(1)\end{array}$ & $\begin{array}{l}3(2) \\
5\end{array}$ & $\begin{array}{l}21(14) \\
8 \text { (1) }\end{array}$ \\
\hline & Total & $18(8)$ & $21(5)$ & $19(2)$ & $58(15)^{*}$ \\
\hline
\end{tabular}

*In parentheses number of patients with fracture of humerus.

There were 29 patients in whom wasting and weakness was attributed to traction or blunt injury of the radial nerve; in 21 both the brachioradialis and the extensors of the wrist and fingers were affected in a degree varying from paralysis to moderate weakness. All but three had sensory loss of hand and forearm, or both. In the remaining eight patients, only the extensors of the wrist and fingers were affected and three had hypaesthesia and hypalgesia of the appropriate part of the hand (Table 1). The brachial triceps muscle was spared in all patients but one.

The pattern of sensory loss in the hand and fingers in 39 patients with sensory disturbances varied (Fig. 2). In one-third there was hypaesthesia and hypalgesia, or both, in the three radial fingers (Fig. 2,3 ). In nearly half, sensory disturbances were confined to the thumb (Fig. 2,1). When the posterior cutaneous forearm branch of the radial nerve was involved the area of disturbed sensation corresponded fairly well with that depicted in anatomical textbooks.

2 ELECTROMYOGRAPHIC OBSERVATIONS (Table 2) The number of motor units activated at full effort was well below normal. There were 'single oscillations' in most of the patients, and in one-third there was no voluntary activity in the brachioradialis and the extensor digitorum muscles, or both in the first

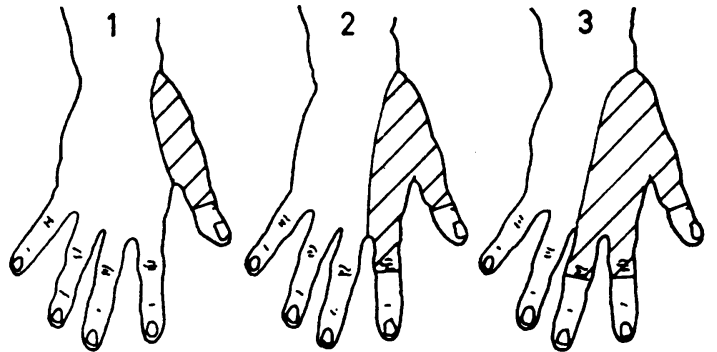

FIG. 2. Distribution of sensory disturbances in the hand and fingers (hypaesthesia and hypalgesia, or both) in patients with radial nerve palsy. In the Table below the number in parentheses indicates the additional involvement of the posterior cutaneous nerve of the forearm. (Pattern: (1) $=$ thumb, (2) = index finger, (3) = middle finger.)

\begin{tabular}{lrrrr}
\hline \multicolumn{1}{c}{ Pattern } & \multicolumn{4}{c}{ Number of patients } \\
\cline { 2 - 5 } & 1 & 2 & 3 & Total \\
\hline Compression during sleep & $10(3)$ & $1(0)$ & $7(4)$ & $18(7)$ \\
Fracture of humerus & $5(4)$ & $3(1)$ & $5(3)$ & $13(8)$ \\
Others & $4(1)$ & $1(0)$ & $3(2)$ & $8(3)$ \\
\hline Total & $19(8)$ & $5(1)$ & $15(9)$ & $39(18)$ \\
\hline
\end{tabular}

investigation. The amplitude of the pattern at full effort was less than $50 \%$ of normal in nearly half of the muscles showing voluntary activity.

Spontaneous discharges of short duration (fibrillation potentials) were found in about $80 \%$ of the brachioradialis and extensor digitorum communis muscles investigated. Among the patients with compression during sleep, signs of denervation occurred in 19 with symptoms for more than two weeks; five of seven patients without fibrillation potentials in the first examination were reinvestigated two weeks later and signs of denervation were then present.

Other signs of disintegration of the motor unit, such as polyphasic potentials and increased mean duration of the action potentials, did not occur in patients with sleep palsies in early or later examinations. They were present in some patients with other types of radial nerve injury in the first examination (three to seven months after injury, Table 2) and occurred in all patients reinvestigated four months to two years after the onset of the palsy.

3 MOTOR AND SENSORY CONDUCTION a. Patients with compression of the radial nerve during sleep One patient (case 19) with a typical Saturday-night palsy was examined 10 times during the period from two days after the onset of the palsy until complete recovery three months later (Figs. 3 and 4): the patient, a 45-year-old travelling agent, awoke with 
TABLE 2

ELECTROMYOGRAPHIC FINDINGS IN 58 PATIENTS WITH RADIAL NERVE PALSY

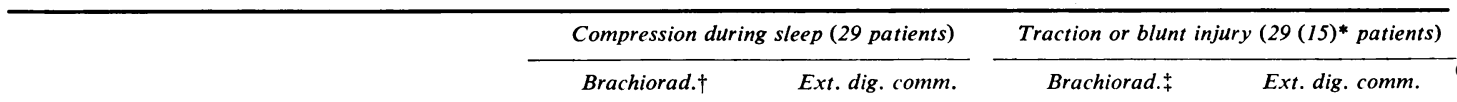

\begin{tabular}{llr}
\hline Number of & muscles affected & 24 \\
\hline Pattern at & No or slight loss of motor units & 0 \\
full effort & Severe loss of motor units & 14 \\
& No activity & 9 \\
\hline
\end{tabular}

Reduced amplitude of pattern at full effort ( $>50 \%)$

Fibrillation potentials and positive sharp waves

or both

Increased mean action potential duration $(>20 \%)$

Increased incidence of polyphasic potentials $(>12 \%)$

15
0

$15 \quad 20$

0

29
3
19
7
11

$21(14)$

*In parentheses number of patients with sequel of fracture of the humerus.

†In one not examined.

$\ddagger$ In two not examined.

EVOKED ACTION POTENTIALS FROM M. BRACHIO-RADIALIS

by stimulation at

Days after

onset

2

at full effort

Axilla

Elbow

33

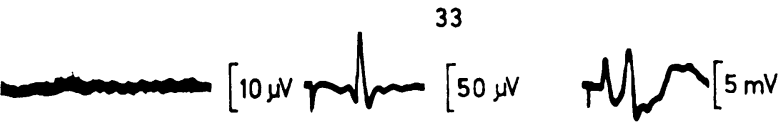

5

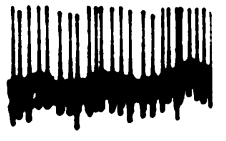

$[10 \mu \mathrm{V} r \sqrt{20 \mu v}$

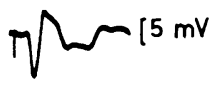

25
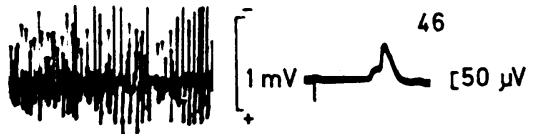

0 10 20msec
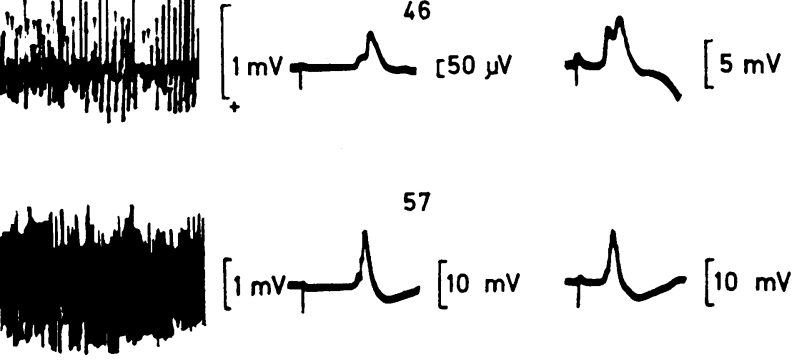

52
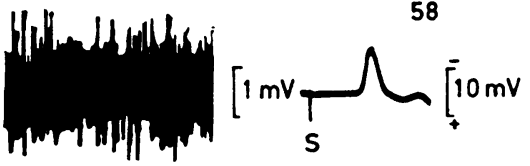

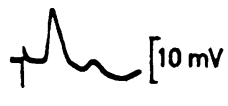

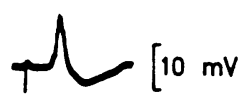

FIG. 3. Electromyographic pattern during full volitional effort and evoked action potentials from the brachioradialis muscle during recovery from radial nerve palsy caused by compression during sleep. The number over each record in the middle denotes the conduction velocity between axilla and elbow. 
Recording from

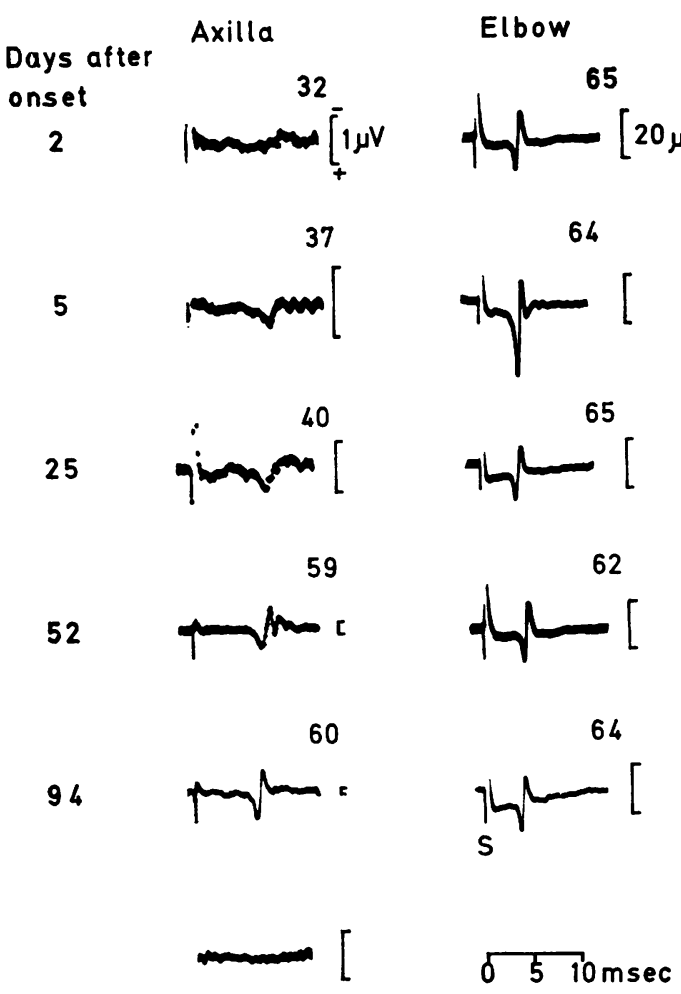

FIG. 4. Sensory conduction velocities during recovery from radial nerve palsy caused by compression during sleep. The number over each record denotes the conduction velocity, to the left between elbow and axilla and to the right between wrist and elbow. The sensory action potentials recorded over the radial nerve at the axilla from the second to the 52nd day after the onset of the palsy are averaged from 500 to 1000 stimuli. The bottom trace represents the average of the same number of sweeps with stimulus zero. Temperature near the nerve $36^{\circ} \mathrm{C}$.

paralysis of the right hand after sleeping in an armchair for one hour while intoxicated with alcohol. Immediately afterwards and at the first examination 48 hours later the brachioradialis and the extensor muscles of the wrist and fingers were paralysed and there was tingling and numbness corresponding to the dorsal aspect of the proximal phalanx of the thumb and the adjacent area of the hand. The electrophysiological examinations were performed on the second, fifth, ninth, 12th, 15th, 20th, 25th, 45th, 52nd, and 94th days after the onset.

The latencies to the forearm muscles innervated by the radial nerve when stimulating at the elbowthat is, below the presumed site of nerve compression-were normal throughout all investigations. 4
They averaged $2.5 \pm 0.03 \mathrm{msec}$ to the brachioradialis and $3.0 \pm 0.1 \mathrm{msec}$ to the extensor digitorum communis muscle, compared with $2.5 \pm 0.1 \mathrm{msec}$ $(\mathrm{N}=9)$ and $2.9 \pm 0.1(\mathrm{~N}=17)$ in normal subjects (Trojaborg and Sindrup, 1969). Similarly, the amplitude of the evoked responses was normal throughout; although there was a considerable variation, the average was $18 \pm 2.7 \mathrm{mV}$. The sensory conduction velocity between wrist and elbow - that is, below the site of compression-was normal at all examinations averaging $64 \mathrm{~m} / \mathrm{sec}$ (S.D. $1.4 \mathrm{~m} / \mathrm{sec}$ ). This illustrates the reproducibility of the method, since the S.D. in normal subjects is three times greater. In contrast, the amplitude of nerve action potentials at the elbow varied considerably, the average being $25 \pm 3.5 \mu \mathrm{V}$, although the motor threshold used for the correct positioning of the 'near nerve' recording electrode varied little and was well below $1 \mathrm{~mA}(0.5 \pm 0.07 \mathrm{~mA}, \mathrm{~N}=10)$. The temperature near the nerve at the wrist and elbow was $36 \pm 0 \cdot 3^{\circ} \mathrm{C}$.

Motor and sensory conduction velocities between axilla and elbow-that is, across the compressed segment of the nerve-were about $50 \%$ of normal values during the first two weeks and returned to normal at about seven weeks (Figs. 3 and 4).

The amplitude of the motor response evoked by supramaximal stimulation varied as much as $40 \%$ in different subjects and in the same patient in different examinations. For this reason, the amplitude of the motor action potential evoked by supramaximal stimulation in the axilla was expressed as the percentage of that evoked by stimulation at the elbow. The recovery of motor fibres was illustrated graphically (Fig. 5). There was a severe reduction of the amplitude of the motor response evoked above the site of the lesion during the first three weeks after the onset, and then it recovered gradually, reaching normal values four to five weeks later.

About seven weeks after the onset of the palsy the patient had recovered nearly completely. The force of the previously paralysed muscles was graded at 5- (Medical Research Council, 1943) and there was no sensory loss. Electrophysiological examination was normal, except the sensory action potential recorded over the radial nerve at the axilla which was less than half normal (Fig. 6).

As in the patient cited above, the distal motor latency and sensory conduction velocity between the wrist and elbow was normal in all but two patients, in whom conduction was abolished in both motor and sensory fibres above the elbow. In the 27 patients in whom the nerve conducted impulses, the distal motor latency and amplitude of the evoked action potential were normal. Similarly, sensory conduction between wrist and elbow and amplitude of the 

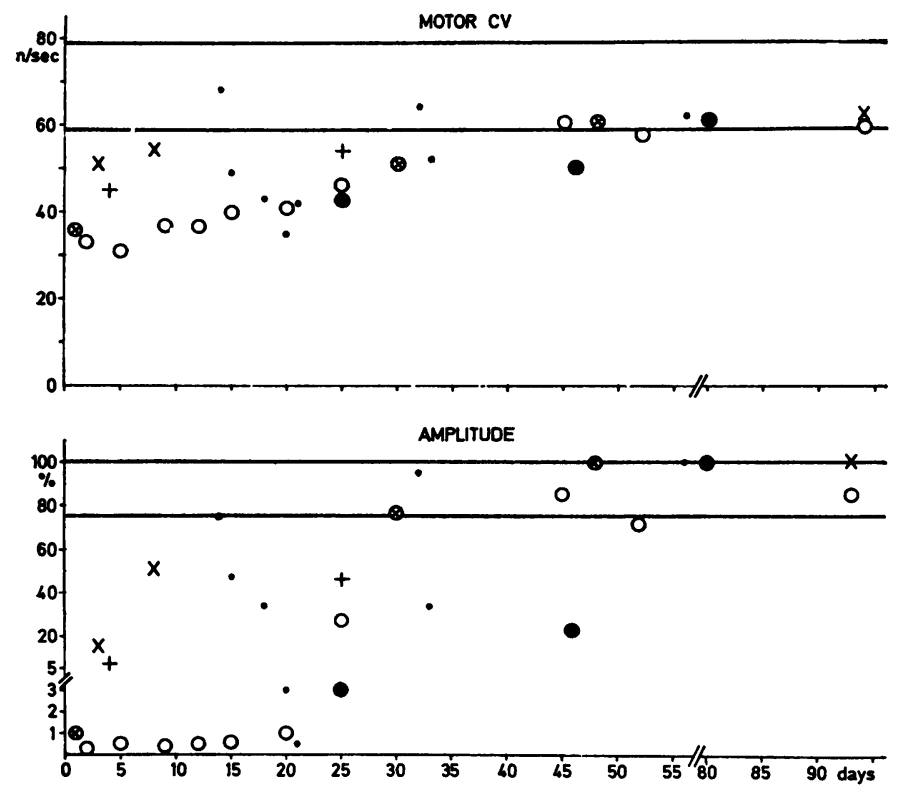

FIG. 5. Above, motor conduction velocities between axilla and elbow as a function of time. Below, amplitude of motor response (m. ext. dig. comm.) evoked by proximal stimulation in per cent of that evoked by distal stimulation. The dots indicate findings in patients seen only once, the open and closed circles, triangles, and crosses findings in different patients reinvestigated once or more often. The solid lines indicate the normal range (Mean + $2 S D)$.

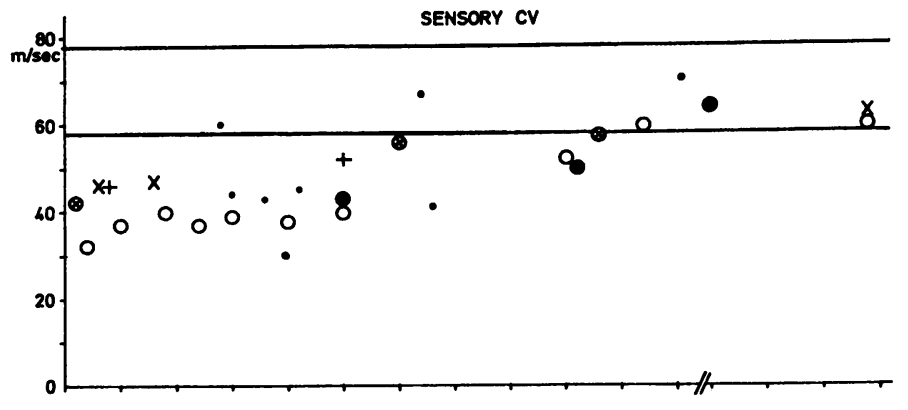

FIG. 6. Above, sensory conduction velocities between the elbow and axilla in patients with radial palsies secondary to

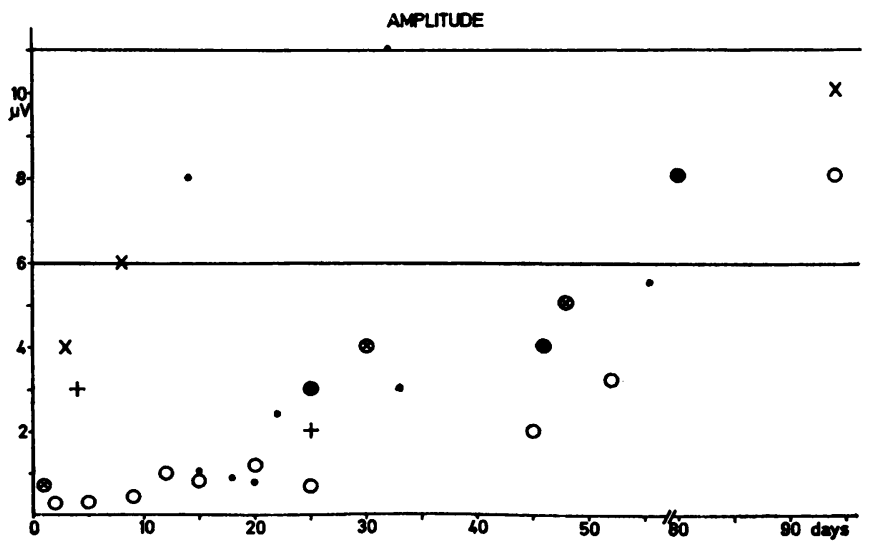
compression during sleep, as a function of time. Below, amplitude of nerve action potentials recorded at the axilla when stimulating the nerve at the wrist. Symbols as in Fig. 5. 
sensory action potential at the elbow were normal (Table 3).

The individual values for motor and sensory conduction velocities between axilla and elbow as well as the amplitude of the responses were plotted as a function of time (Figs. 5 and 6). As a whole, the pattern of recovery was rather uniform for nearly all patients - that is, normal values for conduction rates as well as for amplitudes of evoked responses were reached about seven weeks after the onset. In two patients full recovery occurred after two and five weeks.

Motor and sensory function was abolished in four patients. In two of these, action potentials could be evoked below, but not above the elbow, and, in two others, neither below nor above. Unfortunately, none of these patients was reinvestigated electrophysiologically, but clinical examination in the two with longstanding palsies (four and nine months) showed complete recovery one and one and a half years after the onset.

b. Patients with radial nerve palsy attributed to traction or blunt injury (Tables 4 and 5) When both motor and sensory conduction were abolished at the first examination, motor conduction recovered before sensory (cases 3, 4, 9, 12, 15, and 17). The earliest time at which motor fibres showed signs of reinnervation was three and a half to five months after the time of the injury (cases $3,4,12,15$, and 17) and for the sensory fibres 12 to 15 months (cases 5 and 17) when fibres to the extensor indicis muscle also conducted impulses.

In 10 of 12 patients with fracture of the shaft of the humerus, sensory conduction was abolished at the first examination. They had hypaesthesia and hypalgesia corresponding to the posterior cutaneous nerve of the forearm and the superficial branch, or both. In two patients (cases 15 and 22) without sensory loss clinically, sensory conduction was normal but the amplitude of sensory action potentials was below $1 \mu \mathrm{V}$ and could be discriminated only by an averaging technique. At repeated examination after neurolysis in case 15 no sensory action potentials could be discriminated over the radial nerve at the elbow and sensory loss was also present clinically.

A typical example of a 'lesion in continuity' is described below.

Case 17, a 56-year-old Irish horsemaster, fell from a truck on 24 April 1967. For about one hour his left arm was compressed between the ground and the truck, about $7 \mathrm{~cm}$ above the elbow. Immediately afterwards and at the first examination three months later, there was paralysis of all muscles innervated by the radial nerve except that the brachial triceps was spared. There was hypaesthesia and hypalgesia of the dorsum of the hand and the three radial fingers as well as the dorsal aspect of the forearm. Electromyography showed no voluntary activity corresponding to the brachioradialis and extensor digitorum communis muscles but there was spontaneous activity of short duration (fibrillation potentials). There was no muscle response when stimulating the nerve at the elbow $(\mathrm{S}=35 \mathrm{~mA})$ and no sensory potential over the radial nerve at the elbow when a supramaximal stimulus was applied at the thumb or wrist (Fig. 7 (1)). On surgical exploration four months after the injury the nerve was found to be intact and electrical stimulation elicited contraction in the brachioradialis but not in the extensor digitorum communis.

Electrophysiological examination 150 days after the injury showed single oscillations in the extensor digitorum muscle and an increased incidence of polyphasic potentials $(19 \%)$. Stimulation of the radial nerve at the elbow revealed a low voltage polyphasic response in the brachioradialis and the extensor digitorum communis muscles with latencies of 14 and $25 \mathrm{msec}$ respectively. The sensory action potential was still absent (Fig. 7 (2)).

Fifteen months after the injury, motor conduction velocity to the brachioradialis and extensor digitorum communis muscles between axilla and elbow was 35\% of normal, and that to the extensor indicis $50 \%$ reduced. Similarly, the sensory conduction velocity between the wrist and elbow was reduced by $50 \%$ and between elbow and axilla by $30 \%$ (Fig. 7 (3)).

TABLE 3

DISTAL MOTOR AND SENSORY CONDUCTION IN RADIAL NERVE AND AMPLITUDE OF EVOKED POTENTIALS IN 27 PATIENTS WITH SATURDAY-NIGHT PALSY

\begin{tabular}{|c|c|c|c|c|c|c|}
\hline & & \multicolumn{2}{|c|}{$\begin{array}{c}\text { Patients with } \\
\text { Saturday-night palsy }\end{array}$} & \multicolumn{2}{|c|}{ Normal subjects* } & \multirow[t]{2}{*}{ No. } \\
\hline & & Mean & $M E$ & Mean & $M E$ & \\
\hline Conduction time (msec) & m. brachioradialis & $2 \cdot 6$ & $0 \cdot 1$ & $2 \cdot 5$ & $0 \cdot 1$ & 9 \\
\hline elbow-muscle & m. extensor dig. comm. & $3 \cdot 1$ & $0 \cdot 1$ & $2 \cdot 9$ & $0 \cdot 1$ & 17 \\
\hline Amplitude $(\mathrm{mV})$ of & m. brachioradialis & 16 & $1 \cdot 6$ & 17 & $2 \cdot 0$ & 9 \\
\hline muscle response & m. extensor dig. comm. & 14 & $1 \cdot 5$ & 16 & $1 \cdot 0$ & 17 \\
\hline \multirow{2}{*}{\multicolumn{2}{|c|}{$\begin{array}{l}\text { Sensory conduction velocity }(\mathrm{m} / \mathrm{sec}) \text {, wrist-elbow } \\
\text { Amplitude }(\mu \mathrm{V}) \text { of sensory action potential at elbow }\end{array}$}} & 63 & $1 \cdot 2$ & 66 & $1 \cdot 0$ & 13 \\
\hline & & 19 & $3 \cdot \overline{5}$ & 32 & 3.4 & 13 \\
\hline
\end{tabular}

*Trojaborg and Sindrup, 1969. 
TABLE 4

DETAILS OF CASES

\begin{tabular}{|c|c|c|c|c|c|c|c|c|c|}
\hline \multirow[t]{2}{*}{ Case } & \multirow[t]{2}{*}{ Age $(y r)$} & \multirow[t]{2}{*}{ Aetiology } & \multirow[t]{2}{*}{$\begin{array}{l}\text { Time after } \\
\text { injury }(m)\end{array}$} & \multicolumn{2}{|c|}{$V s(m / s e c)$} & \multicolumn{2}{|c|}{$V m(m / s e c)$} & \multicolumn{2}{|c|}{$\begin{array}{c}\text { Distal conduction time } \\
(\mathrm{msec})\end{array}$} \\
\hline & & & & $w-e$ & $e-a$ & $a-e \dagger$ & $\begin{array}{c}\text { e-forearm } \\
\text { (ext. indicis) }\end{array}$ & e-muscle $\dagger$ & $\begin{array}{l}\text { extensor } \\
\text { indicis }\end{array}$ \\
\hline $1^{(\mathbf{2 a})}$ & $\begin{array}{l}22 \\
22 \\
\end{array}$ & Constriction by suture & $2^{t}$ & $\begin{array}{l}0^{*} \\
0^{*}\end{array}$ & 二 & 二 & $\begin{array}{l}\mathbf{0} \\
\mathbf{0}\end{array}$ & $\begin{array}{l}9.0 \\
10.0\end{array}$ & $\begin{array}{l}\mathbf{0} \\
\mathbf{0}\end{array}$ \\
\hline $2^{(1)}$ & 42 & Blunt injury & $\frac{1}{2}$ & 0 & - & - & - & $3 \cdot 3$ & - \\
\hline $3^{(3)}$ & $\begin{array}{l}16 \\
16 \\
17 \\
\end{array}$ & Supracond. fracture of humerus & $\begin{array}{l}1 \\
4 \\
9\end{array}$ & $\begin{array}{l}0^{*} \\
0^{*} \\
0^{*}\end{array}$ & - & $\frac{0}{-}$ & $\begin{array}{r}0 \\
0 \\
20\end{array}$ & $\begin{array}{c}0 \\
18.0 \\
5.0\end{array}$ & $\begin{array}{l}0 \\
0 \\
3 \cdot 5\end{array}$ \\
\hline$\overline{4^{(1)}}$ & $\begin{array}{l}35 \\
35 \\
35 \\
\end{array}$ & Blunt injury & $\begin{array}{l}1 \\
31 \\
6 \\
\end{array}$ & $\begin{array}{l}0^{*} \\
0 \\
0 \\
\end{array}$ & $\begin{array}{l}\mathbf{0} \\
\mathbf{0} \\
\mathbf{0} \\
\end{array}$ & $\begin{array}{l}24 \\
48 \\
50 \\
\end{array}$ & $\begin{array}{l}0 \\
0 \\
0 \\
\end{array}$ & $\begin{array}{l}7 \cdot 0 \\
2 \cdot 4 \\
4 \cdot 0 \\
\end{array}$ & $\begin{array}{l}\mathbf{0} \\
0 \\
0\end{array}$ \\
\hline $5^{(3)}$ & $\begin{array}{l}14 \\
15 \\
15 \\
\end{array}$ & Pressure? & $\begin{array}{r}1 \\
6 \\
12 \\
\end{array}$ & $\begin{array}{r}0^{*} \\
0^{*} \\
61^{*}\end{array}$ & $\overline{\bar{Z}}$ & $\frac{7}{65}$ & $\underline{-}$ & $\begin{array}{l}3 \cdot 5 \\
3.0 \\
3.5\end{array}$ & $\begin{array}{l}0 \\
0 \\
-\end{array}$ \\
\hline$\overline{6^{(1)}}$ & $\begin{array}{l}22 \\
24\end{array}$ & Fracture of humerus & $27^{1 \frac{1}{2}}$ & $\begin{array}{r}0 \\
49 \\
\end{array}$ & 二 & - & $\overline{43}$ & $\begin{array}{r}10 \cdot 0 \\
3.0 \\
\end{array}$ & $\overrightarrow{3 \cdot 1}$ \\
\hline $7^{(1)}$ & $\begin{array}{l}45 \\
47\end{array}$ & Fracture of humerus & $\begin{array}{r}2 \\
30\end{array}$ & $\begin{array}{c}0 \\
44^{*}\end{array}$ & $\underline{-}$ & $\underline{0}$ & $\begin{array}{r}0 \\
41\end{array}$ & $\begin{array}{l}0 \\
3 \cdot 5\end{array}$ & $\begin{array}{l}0 \\
2 \cdot 5\end{array}$ \\
\hline $8^{(2 a)}$ & $\begin{array}{l}45 \\
47\end{array}$ & Fracture of humerus & $\begin{array}{r}2 \\
21 \\
\end{array}$ & $\begin{array}{r}0 \\
43 \\
\end{array}$ & $\underline{0}$ & $\frac{0}{-}$ & $\begin{array}{r}0 \\
38 \\
\end{array}$ & $\begin{array}{l}0 \\
4 \cdot 0 \\
\end{array}$ & $\begin{array}{l}0 \\
2 \cdot 0 \\
\end{array}$ \\
\hline$\overline{9(1)}$ & $\begin{array}{l}52 \\
52\end{array}$ & Fracture of humerus & $\begin{array}{l}2 \\
5\end{array}$ & $\begin{array}{l}0 \\
0^{*}\end{array}$ & $\underline{\mathbf{0}}$ & 31 & $\underline{0}$ & $\begin{array}{l}7.5 \\
7 \cdot 9\end{array}$ & - \\
\hline$\overline{10^{(28)}}$ & 60 & Injection (i.m.) & 2 & $0^{*}$ & - & - & - & 9.0 & - \\
\hline$\overline{11^{(28)}}$ & 9 & Supracond. fracture of humerus & $2 \frac{1}{2}$ & $0^{*}$ & - & - & $\mathbf{0}$ & $15 \cdot 0$ & $\mathbf{0}$ \\
\hline$\overline{12^{(1)}}$ & $\begin{array}{l}32 \\
32\end{array}$ & Fracture of humerus & $\begin{array}{l}2 \frac{1}{2} \\
4\end{array}$ & $\begin{array}{l}\mathbf{0} \\
\mathbf{0}\end{array}$ & $\begin{array}{l}0 \\
-\end{array}$ & $\frac{0}{-}$ & $\begin{array}{l}0 \\
0\end{array}$ & $\begin{array}{c}0 \\
30.0\end{array}$ & $\begin{array}{ll}0 & \overline{0} \\
0 & 0 \\
\end{array}$ \\
\hline$\overline{13^{(1)}}$ & 51 & Fracture of humerus & 3 & $0^{*}$ & 0 & $\mathbf{0}$ & $\mathbf{0}$ & 0 & $0 \stackrel{0}{0}$ \\
\hline $14^{(2 a)}$ & 19 & Fracture of humerus & 3 & $0^{*}$ & - & - & 0 & $13 \cdot 2$ & 0 षै \\
\hline $15^{(3 b)}$ & $\begin{array}{l}54 \\
54\end{array}$ & Fracture of humerus & $\begin{array}{l}3 \\
4 \\
\end{array}$ & $\begin{array}{r}57^{*} \\
0^{*}\end{array}$ & - & 二 & 二 & $\begin{array}{c}0 \\
10 \cdot 0\end{array}$ & $-\bar{\sigma}$ \\
\hline$\overline{16^{(2 a)}}$ & 43 & Injection (i.m.) & $3 \frac{1}{2}$ & 0 & 0 & 0 & 0 & 0 & 08 \\
\hline$\overline{17^{(1)}}$ & $\begin{array}{l}55 \\
56 \\
56\end{array}$ & Pressure & $\begin{array}{c}3 \frac{1}{2} \\
5 \\
15 \\
\end{array}$ & $\begin{array}{c}0 \\
0^{*} \\
33^{*}\end{array}$ & $\begin{array}{c}0 \\
0 \\
50^{*}\end{array}$ & $\frac{0}{43}$ & $\begin{array}{c}0 \\
0 \\
33(a-e)\end{array}$ & $\begin{array}{r}0 \\
25 \cdot 0 \\
4 \cdot 5\end{array}$ & $\begin{array}{ll}0 & 0 \\
0 & \grave{1} \\
- & 0\end{array}$ \\
\hline$\overline{18^{(\mathrm{a} a)}}$ & 53 & Fracture of humerus & $4 \frac{1}{2}$ & $0^{*}$ & 0 & $\mathbf{0}$ & 0 & 0 & $0=$ \\
\hline $19^{(2 \mathrm{a})}$ & $\begin{array}{l}48 \\
49 \\
49\end{array}$ & Fracture of humerus & $\begin{array}{r}5 \\
19 \\
23\end{array}$ & $\begin{array}{c}0 \\
33^{*} \\
45^{*}\end{array}$ & $\frac{0}{38^{*}}$ & $\frac{33}{43}$ & $\begin{array}{r}0 \\
31 \\
-\end{array}$ & $\begin{array}{l}4 \cdot 0 \\
4.0 \\
5.0\end{array}$ & $\begin{array}{l}0 \\
6.0 \\
-\end{array}$ \\
\hline$\overline{20^{(1)}}$ & 70 & Fracture of humerus & 7 & 0 & 0 & 0 & $\mathbf{0}$ & 0 & 0 \\
\hline$\overline{21^{(1)}}$ & 38 & Fracture of humerus & 7 & 0 & 0 & 15 & 0 & $25 \cdot 0$ & 0 \\
\hline $22^{(2 b)}$ & 31 & Fracture of humerus & 19 & $56^{*}$ & $84^{*}$ & 46 & - & $7 \cdot 5$ & - \\
\hline $\begin{array}{l}\text { Normals } \\
\text { (16-28 yr) } \\
\text { (Trojaborg }\end{array}$ & d Sindru & p, 1969) & $\begin{array}{l}\text { Mean } \\
\text { S.D. } \\
\text { No. }\end{array}$ & $\begin{array}{l}68 \\
4 \cdot 6 \\
20\end{array}$ & $\begin{array}{l}69 \\
5 \cdot 8 \\
16\end{array}$ & $\begin{array}{l}69 \\
5.0 \\
11\end{array}$ & $\begin{array}{l}62 \\
5 \cdot 1 \\
10\end{array}$ & $\begin{array}{l}2 \cdot 7 \\
0 \cdot 3 \\
26\end{array}$ & $\begin{array}{l}2 \cdot 4 \\
0 \cdot 5 \\
10\end{array}$ \\
\hline
\end{tabular}

$\mathrm{w}=$ wrist, $\mathrm{e}=$ elbow, $\mathrm{a}=$ axilla. $\mathrm{Vs}=$ sensory conduction velocity. $\mathrm{Vm}=$ motor conduction velocity.

*Average technique. +Brachioradialis and ext. dig. comm. muscles or both.

The number in parentheses denotes the presumed site of injury (see Table 6).

(1) Above and (2) below posterior cutaneous nerve of forearm, (2a) with and (2b) without sensory involvement clinically.

(3) $r$. profundus and $r$. superficialis.

In patients in whom the radial nerve conducted impulses in both motor and sensory fibres at the first examination, the conduction velocity was within the normal range in all but one (case 25 , Table 5).

An attempt was made to predict the site of interruption on the basis of clinical and electromyographic findings and this was then correlated with the conduction velocity determinations (Table 6). $\stackrel{\circ}{\circ}$ Motor and sensory conduction between axilla and elbow was determined in 17 patients with Saturday-윽 night palsies; in 10 the conduction velocity was slowed in motor as well as in sensory fibres, was normal in three, and abolished in four. Thus, in $N$ six of the 10 patients, slowing of conduction in the proximal part of the radial nerve was consistent with $\tilde{D}$ 
TABLE 5

DETAILS OF CASES

\begin{tabular}{|c|c|c|c|c|c|c|c|c|}
\hline \multirow[t]{2}{*}{ Case } & \multirow[t]{2}{*}{ Age $(y r)$} & \multirow[t]{2}{*}{ Aetiology } & \multirow{2}{*}{$\begin{array}{l}\text { Time after } \\
\text { injury }(m)\end{array}$} & \multicolumn{2}{|c|}{$V s(\mathrm{~m} / \mathrm{sec})$} & \multirow{2}{*}{$\begin{array}{c}V m(m / s e c) \\
e-f o r e a r m\end{array}$} & \multicolumn{2}{|c|}{ Distal conduction time (msec) } \\
\hline & & & & $w-e$ & $e-a$ & & ext.dig.comm & $\begin{array}{l}\text { extensor } \\
\text { indicis }\end{array}$ \\
\hline $\begin{array}{l}23^{(2 b)} \\
24^{(4)} \\
25^{(4)} \\
26^{(4)} \\
27^{(4)} \\
28^{(4)} \\
29^{(3)}\end{array}$ & $\begin{array}{l}22 \\
68 \\
54 \\
17 \\
19 \\
64 \\
51\end{array}$ & $\begin{array}{l}\text { Traction? } \\
\text { Traction? } \\
\text { Traction? (forced work) } \\
\text { Unknown } \\
\text { Fracture radii } \\
\text { Traction? (forced work) } \\
\text { Fracture radii et ulnae }\end{array}$ & $\begin{array}{l}1 \\
1 \frac{1}{1} \\
1 \frac{1}{4} \\
2 \\
3 \\
4 \\
7\end{array}$ & $\begin{array}{l}69 \\
70 \\
64 \\
66 \\
54 \\
66 \\
57\end{array}$ & $\begin{array}{l}- \\
\frac{-}{64} \\
- \\
-\end{array}$ & $\begin{array}{l}69 \\
57 \\
54 \\
68(a-e) \\
\overline{60} \\
66\end{array}$ & $\begin{array}{l}3 \cdot 0 \\
3 \cdot 5 \\
2 \cdot 6 \\
2 \cdot 3 \\
6 \cdot 0 \\
3 \cdot 5 \\
3 \cdot 2\end{array}$ & $\begin{array}{l}2 \cdot 8 \\
2 \cdot 5 \\
- \\
- \\
\overline{4} \cdot 0 \\
3 \cdot 0\end{array}$ \\
\hline \multicolumn{3}{|c|}{$\begin{array}{l}\text { Normals } \\
\text { (16-28 yr) } \\
\text { (Trojaborg and Sindrup, 1969) }\end{array}$} & $\begin{array}{l}\text { Mean } \\
\text { S.D. } \\
\text { N }\end{array}$ & $\begin{array}{l}68 \\
4 \cdot 6 \\
20\end{array}$ & $\begin{array}{l}69 \\
5 \cdot 8 \\
16\end{array}$ & $\begin{array}{l}62 \\
5 \cdot 1 \\
10\end{array}$ & $\begin{array}{l}2 \cdot 9 \\
0 \cdot 3 \\
17\end{array}$ & $\begin{array}{l}2 \cdot 4 \\
0 \cdot 5 \\
10\end{array}$ \\
\hline
\end{tabular}

$\mathbf{w}=$ wrist, $\mathbf{e}=$ elbow, $\mathbf{a}=$ axilla.

The number in parentheses denotes the presumed site of injury (See Table 6).

(1) Above and (2) below posterior cutaneous nerve of forearm, (2a) with and (2b) without sensory involvement clinically.

(3) r. profundus and superficialis, (4) r. profundus.

the presumed site of injury (Table $6(1,2))$. It is noteworthy however that sensory conduction velocity was slowed in four patients without clinical evidence of sensory loss (Table $6(2 \mathrm{~b})$ ). In three patients, two with and one without sensory loss clinically, sensory and motor conduction velocities were normal in the
(1)

m.brachiorad. m.ext.dig.com. m.ext.indicis
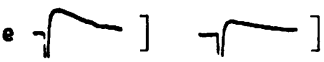

(2)
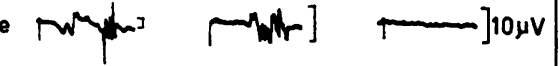

(3)

a<smiles>CCCCCC</smiles>
$\longdiv { 2 5 } 5 0 \mathrm { msec }$

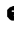<smiles>CCCCCCC(=S)S</smiles>

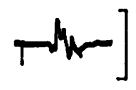<smiles>IC1CCCCC1(I)I</smiles><smiles>[3H][13CH3]</smiles>

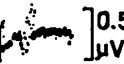
HV $01020 \mathrm{msec}$
Sensory

FIG. 7. Changes in motor and sensory conduction during recovery from total interruption of the radial nerve about $7 \mathrm{~cm}$ proximal to the lateral epicondyle of the humerus. (1) Three months, (2) five months, (3) 15 months after injury. In (1) and (2) sensory recording represents photographic superposition of 15 sweeps; in (3) averaging of 300-500 stimuli. The lowermost trace to the right represents the average of the same number of sweeps with stimulus zero. Temperature near the nerve was $36^{\circ} \mathrm{C}$ at the wrist, $37^{\circ} \mathrm{C}$ at elbow, and $35^{\circ} \mathrm{C}$ at axilla. In (3) the motor conduction velocity to the brachioradialis and extensor digitorum communis muscles between the axilla and elbow was 44 and $43 \mathrm{~m} / \mathrm{sec}$ respectively, and that to the extensor indicis $33 \mathrm{~m} / \mathrm{sec}$. The sensory conduction velocity was $33 \mathrm{~m} / \mathrm{sec}$ between wrist and elbow and $50 \mathrm{~m} / \mathrm{sec}$ between elbow and axilla.

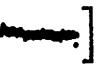

$01020 \mathrm{msec}$ 
TABLE 6

MOTOR (Vm) AND SENSORY (Vs) CONDUCTION VELOCITY IN 58 PATIENTS WITH RADIAL NERVE PALSY CAUSED BY COMPRESSION DURING SLEEP, ${ }^{*}$ TRACTION OR BLUNT INJURY

\begin{tabular}{|c|c|c|c|c|c|c|c|c|c|c|c|c|c|c|}
\hline \multirow{2}{*}{\multicolumn{2}{|c|}{$\begin{array}{c}\text { Presumed site of radial } \\
\text { nerve injury }\end{array}$}} & \multirow[t]{2}{*}{ No. } & \multicolumn{3}{|c|}{$\begin{array}{l}\text { Distal motor conduction } \\
\text { time }(\text { elbow-muscle } \\
(2))\end{array}$} & \multicolumn{3}{|c|}{$V m($ axilla-elbow) } & \multicolumn{3}{|c|}{$V s$ (wrist-elbow) } & \multicolumn{3}{|c|}{$V s($ elbow-axilla $)$} \\
\hline & & & Norm. & Incr. & Abol. & Norm. & Decr. & Abol. & Norm. & Decr. & Abol. & Norm. & Decr. & Abol. \\
\hline \multicolumn{2}{|c|}{$\begin{array}{l}\text { 1. Above posterior cutaneous } \\
\text { nerve of forearm }\end{array}$} & 18 (7) & 7 (6) & 6 & $5(1)$ & $2(2)$ & 3 (1) & $6(1)$ & $6(6)$ & 0 & $12(1)$ & (2) & (1) & $12(1)$ \\
\hline $\begin{array}{l}\text { 2. Below } \\
\text { post. cut. } \\
\text { nerve of } \\
\text { forearm }\end{array}$ & $\begin{array}{l}\text { (a) with sens. } \\
\text { involvem. } \\
\text { (b) without } \\
\text { sensory } \\
\text { involvem. }\end{array}$ & $\begin{array}{l}17(10) \\
10(7)\end{array}$ & $\begin{array}{l}9 \text { (9) } \\
8 \quad(7)\end{array}$ & 4 & $4(1)$ & (1) & 5 (4) & $5(2)$ & $\begin{array}{r}9(9) \\
10(7)\end{array}$ & 0 & $8(1)$ & $2(1)$ & (5) & $\begin{array}{l}9(2) \\
1(1)\end{array}$ \\
\hline \multicolumn{2}{|c|}{$\begin{array}{l}\text { 3. } R \text {. profundus and } \\
\text { supərficialis }\end{array}$} & 4 (1) & 3 (1) & 0 & 1 & - & - & - & 1 (1) & 1 & 2 & - & - & - \\
\hline \multicolumn{2}{|c|}{ 4. R. profundus } & 9 (4) & 8 (4) & 0 & 1 & 1 & 一 & 一 & 8 (4) & 1 & 0 & - & - & - \\
\hline Total & & $58(29)$ & $35(27)$ & 11 & $12(2)$ & $4(3)$ & $14(10)$ & $13(4)$ & $34(27)$ & 2 & $22(2)$ & $4(3)$ & $(10)$ & $22(4)$ \\
\hline
\end{tabular}

first examination (two, four, and eight weeks after onset). These patients recovered dramatically; the only evidence of injury was fibrillation potentials in the brachioradialis and extensor digitorum communis muscles and a slight reduction of the pattern at full effort.

In the patients with radial nerve injury secondary to fracture of the humerus there was also a good relationship between clinical and electrophysiological findings in determining the site, but in patients with other types of injury (Table 5) determination of conduction velocities contributed little to ascertainment of the site of nerve damage.

To estimate whether or not all fibre types were affected equally the velocities of the fastest and slowest conducting fibres were determined whenever possible. The segment of nerve used for this determination was either from wrist to elbow or from wrist to axilla, assuming that the point of stimulation coincided with the stimulating cathode placed at the wrist (Table 7). There was a significant decrease in velocity of both fastest and slowest fibres between wrist and elbow in patients recovering from trau- $\omega$ matic injury (47 to $23 \mathrm{~m} / \mathrm{sec}$ as compared wittor 66 to $42 \mathrm{~m} / \mathrm{sec}$ in normals and in patients wiţ్ 요 Saturday-night palsies). Similarly the decrease conduction between wrist and axilla in patients wit Saturday-night palsies applied to the fastest as well as to the slowest conducting fibres. The actual slowing was obscured by the normal conduction between wrist and elbow, but was otherwise similar to that if patients recovering from traumatic nerve injurs When the amplitude of the sensory action potentiat recorded in the axilla was plotted as a function of conduction velocity between elbow and axilla in patients with Saturday-night paralysis, conduction velocity was severely reduced whenever the amplitude was small. As conduction recovered, there was a steady increase in amplitude of the response recorded above the site of the lesion. Normal amplitude was however sometimes attained later than normal conduction velocity, indicating that some but not all of the fastest conducting fibres had recovered fully (Fig. 8).

TABLE 7

SENSORY CONDUCTION VELOCITY (m/sec) OF THE FASTEST (Vmax) AND SLOWEST (Vmin) FIBRES OF THE RADIAL NERVE

\begin{tabular}{|c|c|c|c|c|c|c|c|c|c|c|c|c|c|c|}
\hline & \multirow[b]{3}{*}{ No. } & \multicolumn{6}{|c|}{ Wrist-Elbow } & \multicolumn{7}{|c|}{ Wrist-Axilla } \\
\hline & & \multicolumn{2}{|c|}{$V \max$} & \multicolumn{2}{|c|}{$V \min$} & \multicolumn{2}{|c|}{ Distance $(\mathrm{cm})$} & \multirow[b]{2}{*}{ No. } & \multicolumn{2}{|c|}{$V \max$} & \multicolumn{2}{|c|}{$V \min$} & \multicolumn{2}{|c|}{ Distance $(\mathrm{cm})$} \\
\hline & & Mean & $M E$ & Mean & $M E$ & Mean & $M E$ & & Mean & $M E$ & Mean & $M E$ & Mean & $M E$ \\
\hline $\begin{array}{l}\text { Normals } \\
\text { Compression during sleep }\end{array}$ & $\begin{array}{l}12 \\
21\end{array}$ & $\begin{array}{l}66 \\
64\end{array}$ & $\begin{array}{l}1 \cdot 3 \\
1 \cdot 0\end{array}$ & $\begin{array}{l}42 \\
44\end{array}$ & $\begin{array}{l}0.9 \\
1 \cdot 2\end{array}$ & $\begin{array}{l}22 \cdot 9 \\
24 \cdot 0\end{array}$ & $\begin{array}{l}0.5 \\
0.3\end{array}$ & $\begin{array}{l}10 \\
13\end{array}$ & $\begin{array}{l}66 \\
50\end{array}$ & $\begin{array}{l}1 \cdot 1 \\
1 \cdot 4\end{array}$ & $\begin{array}{l}47 \\
35\end{array}$ & $\begin{array}{l}1 \cdot 4 \\
2 \cdot 3\end{array}$ & $\begin{array}{l}37 \cdot 6 \\
40 \cdot 2\end{array}$ & $\begin{array}{l}1 \cdot 3 \\
0 \cdot 4\end{array}$ \\
\hline Traumatic injuries & 9 & 47 & $3 \cdot 3$ & 23 & $2 \cdot \overline{3}$ & 21.4 & 0.6 & 4 & \multicolumn{2}{|c|}{$\begin{array}{l}\text { Range } \\
39-64\end{array}$} & \multicolumn{2}{|c|}{$\begin{array}{l}\text { Range } \\
20-35\end{array}$} & \multicolumn{2}{|c|}{$\begin{array}{c}\text { Range } \\
35 \cdot 8-39 \cdot 4\end{array}$} \\
\hline
\end{tabular}




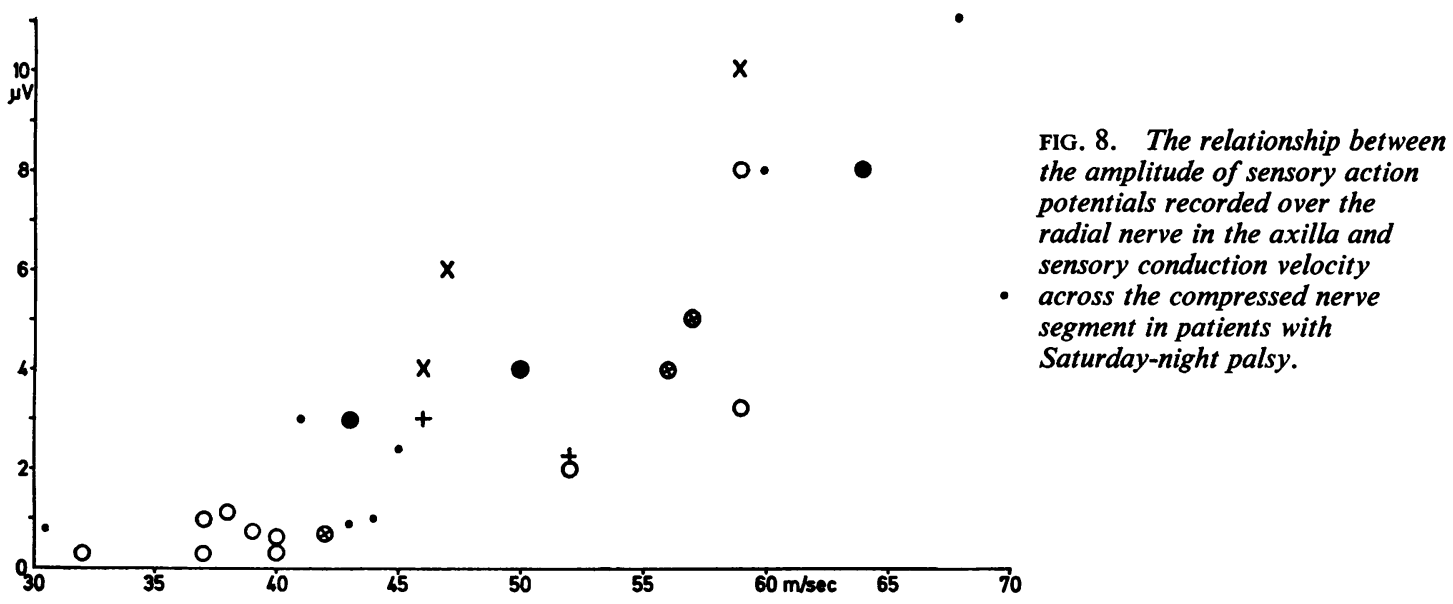

DISCUSSION

1 SATURDAY-NIGHT PALSY a. Variations in sensory and motor loss The clinical manifestations varied in patients with compression of the radial nerve during sleep. The lesion in the sleep palsies is assumed to occur at the lateral border of the humerus, where the radial nerve pierces the lateral intermuscular septum, or just below this; here the nerve is placed superficially and closely related to the humerus. Compression here causes paresis of the brachioradialis and extensor muscles of the wrist and fingers (Sunderland, 1945). Sensory loss is expected to be limited to the dorsum of the wrist, hand, thumb, and $21 / 2$ radial fingers as far as the second phalanx. However, only 10 of 29 patients fulfilled this pattern; in seven others the clinical picture was compatible with the deduction of Sunderland (1945), except for the sparing of sensory fibres (Table 1). In the other 12 patients the clinical findings pointed to injury at a higher level due to involvement of the posterior cutaneous nerve of the forearm (seven patients) or to a lower level, with sparing of the brachioradialis muscle (five patients). Assuming that the site of compression proposed by Sunderland is correct, the variation in clinical pattern might be due to (1) variable susceptibility of motor and sensory branches to pressure, (2) position of the fibres in the nerve, or (3) anatomical variation.

1. It is clinically evident in both man and animal that sensory fibres are less susceptible to pressure than motor fibres (Seddon, 1942; Denny-Brown and Brenner, 1944; Sunderland, 1945; Mayer and Denny-Brown, 1964). However, it is unlikely that sensory fibres would survive when motor nerve fibres are compressed to a degree causing muscular paralysis. In fact in all my patients there was equal slowing in both motor and sensory fibres across the site of compression even when there was no evidence of clinical deficit.

2. The organization of sensory fibres in the antero-central and medial portions of the radial nerve has been said to account for the less pronounced disorder of sensory than of motor fibres, thus also explaining the faster recovery of sensation (Sunderland, 1945). However, the determination of motor and sensory conduction velocity across the affected nerve segment showed a parallel course of recovery in my patients.

3. Variable injury of the posterior cutaneous branch of the forearm by the compression might be due to anatomical variations. Linell (1921) found that the origin from the main trunk varied between 8 and $30 \mathrm{~cm}$ with reference to the acromion. There is no reliable estimate of the incidence of these variations. According to the findings presented here the nerve branches off more distally in $24 \%$ of individuals (seven of 29 patients had sensory loss in the distribution of the posterior cutaneous nerve).

The sparing of the brachioradialis muscle in five patients may have been due to branching of the fibres to this muscle above the site of compression. The origin varies from 22 to $28 \mathrm{~cm}$ below the acromion (Linell, 1921). According to my findings, more proximal branching occurs in $17 \%$.

About one third of the patients with Saturdaynight palsy did not have clinical sensory loss, even though electrophysiological examination showed evidence of sensory nerve injury in most. The divergence between clinical and electrophysiological findings cannot be explained by variation in the site of division of the radial nerve into superficial and 
posterior interosseous branches. The lack of sensory involvement clinically might be due to anatomical anomalies with respect to cutaneous innervation or to cutaneous anastomoses. The cutaneous area generally supplied by the superficial branch may be innervated by the posterior cutaneous nerve of the forearm, rarely by the median nerve, or partly by the musculocutaneous nerve due to free anastomoses (Hutton, 1906; Stopford, 1918; Linell, 1921 ; Sittig, 1928).

b. Motor and sensory conduction Saturday-night paralysis is characterized by a transient block and is usually classified as neuropraxia, a short-lived palsy-so short that recovery cannot be explained in terms of true regeneration (Seddon, 1942). The electrophysiological events equivalent to the clinical pattern consist of normal excitability below and inexcitability above the nerve lesion (Denny-Brown and Brenner, 1944; Bauwens, 1960). Findings in animals suggest that the block is secondary to ischaemia causing a local demyelination (DennyBrown and Brenner, 1944), which in turn gives rise to either a complete block or a slowing in propagation of impulses through the damaged segment, with normal conduction both above and below the lesion (Mayer and Denny-Brown, 1964). That local demyelination causes slowing in conduction is now well established in experimental animals (McDonald, 1963; Gilliatt, 1966).

There have been few reports of conduction studies in humans with pressure palsies. Harvey and Kuffler (1944) stimulated the radial nerve at the spiral groove in one patient with sleep induced compression palsy. They were unable to evoke a muscle response during the first week after the onset, but, three weeks later, the patient had recovered clinically and the motor response was of normal size and shape. Gassel and Diamantopoulos (1964) investigated four patients with Saturday-night palsy; the calculation of motor conduction velocity was invalidated in two due to a decrease in amplitude of the motor responses and change in their shape when stimulating the radial nerve above the site of compression, but was normal in two others.

Sensory conduction has been investigated by Downie and Scott (1964). In their four patients a sensory action potential could not be discriminated above the site of lesion in two, whereas conduction velocity was normal in the two others. Similar preliminary findings were reported by Trojaborg and Sindrup (1967). However the findings of normal sensory conduction in the early state of sleep palsy might be due to a misinterpretation of the recording. When sensory fibres of the radial nerve are stimulated at the proximal phalanx of the thumb, $50 \%$ of the potential recorded over the radial nerve at the axilla is due to spread from the median nerve fibres stimulated simultaneously (Trojaborg and Sindrup, 1969). Similarly when the radial nerve is stimulated at the wrist with a 4 to $5 \mathrm{~cm}$ long 'pipe-cleaner' laid around the radial aspect of the wrist (Downie and Scott, 1964), simultaneous activation of the median nerve occurs when the stimulus is supramaximal for sensory fibres of the radial nerve. With increasing stimulus strength there is a steady increase in amplitude of the potential recorded over the median nerve (Fig. 9). Thus if there is a block of conduction in radial nerve fibres the potential picked up above the site of the lesion may represent spread from the median nerve and could account for the finding of normal conduction velocity. However when, as in the study presented here, the strength of the stimulus applied through needle electrodes placed at the wrist is less than $15 \mathrm{~mA}$, contamination from the median nerve fibres could be avoided; a stimulus of $6 \mathrm{~mA}$ is considered supramaximal in normal subjects (Trojaborg and Sindrup, 1969).

The findings reported here of slowing in conduction in patients with radial nerve palsy secondary to ischaemia agree with the observations in animals and are consistent with the assumption that local de myelination is the cause of paralysis. The wide spread fibrillation potentials in the paretic musclesp do not invalidate this statement, as they may occuf even without axonal damage, as in experimenta botulinum intoxication (Thesleff, 1960; Josefssorb and Thesleff, 1961).

It is likely that there was additional damage of axons followed by Wallerian degeneration in patient with longstanding sleep palsies where the electrophysiological examination demonstrated total interruption of motor and sensory conduction above and below the site of the compression. In the patient with sleep palsy studied by Dejerine and Bernheim (1899) pathological examination showed Wallerian degeneration and similar findings were observed in animal experiments (Denny-Brown and Brenner, 1944; Mayer and Denny-Brown, 1964). Unfortunately the present study does not clarify this question since there was no electrophysiological follow-up of the patients with this type of nerve injury.

2 NERVE LESIONS IN CONTINUITY In patients with fracture of the shaft of the humerus the site of injury of the radial nerve corresponds to the osseous spiral groove and there was total interruption of motor function distal to this point. Decrease of sensation to testing by pinprick and cotton wool was limited to the dorsum of the hand and one, two, or all three radial fingers with additional involvement of a small area of the dorsal aspect of the forearm in half the 

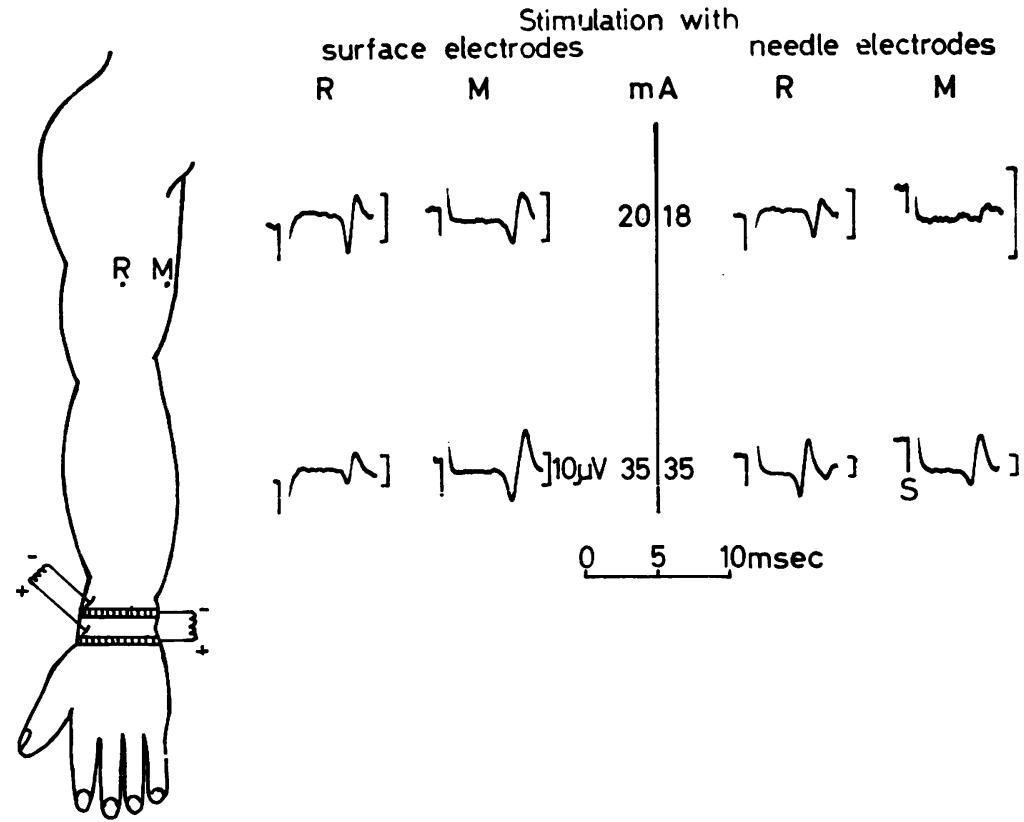

FIG. 9. Nerve action potentials recorded simultaneously over the radial $(\mathrm{R})$ and median (M) nerves in the middle of the upper arm, after stimulating the radial nerve at the wrist with surface and needle electrodes. The surface electrodes were wrapped around the wrist, covering the lateral half of the forearm on both volar and dorsal surfaces. Stimuli applied through surface electrodes evoked potentials in both radial and median nerves; the amplitude of the median nerve action potential increased with increasing strength of stimulus (left upper record $20 \mathrm{~mA}$, lower record $35 \mathrm{~mA}$ ). Stimuli applied through needle electrodes gave rise to a barely discernible potential over the median nerve (right upper record $18 \mathrm{~mA}$ ). However, when the stimulus strength was raised to $35 \mathrm{~mA}$ (right lower record) an action potential was visualized over the median nerve as well. The increase in amplitude of the potential over the radial nerve was due to pick-up from the median nerve.

patients. The electrophysiological examination confirmed the clinical findings; there was no response in the brachioradialis and extensor muscles of wrist and fingers and it was not possible to discriminate a sensory potential by stimulation of the nerve. Similar findings were observed in patients with other types of severe blunt injury to the nerve.

Changes in motor conduction during recovery from partial or total nerve interruption were first reported by Hodes, Larrabee, and German (1948). They described abnormalities in the summated muscle action potentials evoked by stimulation in patients with median and ulnar nerves injury. The findings included polyphasia, decrease in amplitude, increase in duration of the response and in conduction time with return to normality of the evoked responses approximately paralleling the clinical improvement. Similar findings have been reported in a small number of patients with radial nerve injury
(Gassel and Diamantopoulos, 1964). The study presented in this report confirms previous observations in motor fibres and adds information about recovery in sensory nerve fibres. In the three patients with traumatic radial nerve injury examined six to 11 months after the onset of the palsy Downie and Scott (1964) were not able to discriminate a sensory action potential and there was no follow-up.

According to my findings the rate of recovery is equal in motor and sensory fibres of the radial nerve, when comparing a comparable length of nerve. Thus, using the extensor indicis muscle as an indicator for the return of motor function, whenever it was possible to evoke a muscle response a sensory action potential could also be recorded. The data are inadequate for a more exact determination, but the time course of recovery based on electrophysiological criteria was consistent with an outgrowth of nerve fibres of about $1 \mathrm{~mm}$ per day, in agreement 
with the growth in the radial nerve of 1 to $2 \mathrm{~mm}$ per day found clinically (Seddon, Medawar, and Smith, 1943).

The patients in whom the radial nerve injury was attributed to traction or mild blunt trauma did not show significant changes in motor or sensory conduction; the nerve injury was evident on clinical and electromyographic findings only. In five patients motor impairment was limited to muscles innervated by the posterior interosseous nerve. In these patients there was no electrophysiological evidence of entrapment of the nerve similar to the observation reported in one patient by Goldman, Honet, Sobel, and Goldstein (1969). It is likely that the nerve damage affected mainly the axons with little or no injury of the myelin sheaths, and sparing some of the fastest conducting fibres.

\section{REFERENCES}

Andersen, V. O. (1966). In: Annual Report of the Institute of Neurophysiology of the University of Copenhagen. Universitetsforlaget: Copenhagen.

Bauwens, P. (1960). Electrodiagnostic definition of the site and nature of peripheral nerve lesions. Ann. phys. Med., 5, 149-152.

Buchthal, F. (1957). In: An Introduction to Electromyography. Gyldendal: Copenhagen.

Buchthal, F., and Rosenfalck, A. (1966). Evoked action potentials and conduction velocity in human sensory nerves. Brain Res., 3, 1-119.

Buchthal, F., and Rosenfalck, P. (1966). Spontaneous electrical activity of human muscle. Electroenceph. clin. Neurophysiol., 20, 321-336.

Dejerine, J. J., and Bernheim, H. M. (1899). Sur un cas de paralysie radiale par compression, suivi d'autopsie. Rev. Neurol. clin., 7, 785-788.

Denny-Brown, D., and Brenner, C. (1944). Paralysis of nerve induced by direct pressure and by tourniquet. Arch. Neurol. Psychiat. (Chic.), 51, 1-26.

Downie, A. W., and Scott, T. R. (1964). Radial nerve conduction studies. Neurology (Minneap.), 14, 839-843.

Downie, A. W., and Scott, T. R. (1967). An improved technique for radial nerve conduction studies. J. Neurol. Neurosurg. Psychiat., 30, 332-336.

Gassel, M. M., and Diamantopoulos, E. (1964). Pattern of conduction times in the distribution of the radial nerve. Neurology (Minneap.), 14, 222-231.

Gilliatt, R. W. (1966). Disorders of peripheral nerve. J. roy. Coll. Phycns Lond., 1, 50-55.
Goldman, S., Honet, J. C., Sobel, R., and Goldstein, A. S. (1969). Posterior interosseous nerve palsy in the absence of trauma. Arch. Neurol. (Chic.), 21, 435-441.

Harvey, A. M., and Kuffler, S. W. (1944). Motor nerve function with lesions of peripheral nerve. A quantitive study. Arch. Neurol. Psychiat. (Chic.), 52, 317-322.

Hodes, R., Larrabee, M. G., and German, W. J. (1948). The human electromyogram in response to nerve stimulation and the conduction velocity of motor axons; studies on normal and on injured peripheral nerves. Arch. Neurol. Psychiat. (Chic.), 60, 340-365.

Hutton, W. K. (1906). Remarks on the innervation of the dorsum manus with special reference to certain rare abnormalities. J. Anat. (Lond.), 40, 326-331.

Jebsen, R. H. (1966). Motor conduction velocity of distal radial nerve. Arch. phys. Med., 47, 12-16.

Josefsson, J. D., and Thesleff, S. (1961). Electromyographic findings in experimental botulinum intoxication. Acta physiol. scand., 51, 163-168.

Linell, E. A. (1921). The distribution of nerves in the upper limb with reference to variabilities and their clinical significance. J. Anat. (Lond.), 55, 79-112.

Mayer, R. F., and Denny-Brown, D. (1964). Conduction velocity in peripheral nerve during experimental demyelination in the cat. Neurology (Minneap.), 14, 714-726.

McDonald, W. I. (1967). Structural and functional changes in human and experimental neuropathy. In: Modern Trends in Neurology, Vol. 3, pp. 145-164, edited by D. Williams. London.

Medical Research Council. (1943). Aids to the Investigation of Peripheral Nerve Injuries. London. H.M. Stationery Office, 48 pp.

Seddon, H. J. (1942). A classification of nerve injuries. Brit med. J., 2, 237-239.

Seddon, H. J., Medawar, P. B., and Smith, H. (1943). Rate of regeneration of peripheral nerves in man. J. Physio (Lond.), 102, 191-215.

Sittig, O. (1928). Atypische Ausbreitung des sensiblem Radialisgebietes an der Hand. Mschr. Psychiat. Neurol. 67, 229-233.

Stopford, J. S. B. (1918-19). The variation in distribution of the cutaneous nerves of the hand and digits. J. Anat. (Lond.), 53, 14-25.

Sunderland, S. (1945). Traumatic injuries of peripheral nerves. I. Simple compression injuries of the radial nerve. Brain, 68, 56-72.

Thesleff, S. (1960). Supersensitivity of skeletal muscle produced by botulinum toxin. J. Physiol. (Lond.), 151, 598-607.

Trojaborg, W., and Sindrup, E. H. (1967). Electrophysiological investigation in radial nerve palsy. Abstract International Meeting on Electromyography, Glasgow.

Trojaborg, W., and Sindrup, E. H. (1969). Motor and sensory conduction in different segments of the radial nerve in normal subjects. $J$. Neurol. Neurosurg. Psychiat., 32, 354-359. 